\section{SCIENCE IN SOCIAL AND INTER- NATIONAL PLANNING, WITH SPECIAL REFERENCE TO INDIA*}

\author{
By Prof. MEGHNAD SAHA, F.R.S. \\ University of Calcutta
}

\begin{abstract}
7 HE League of Nations was formed after the War of 1914-18 to promote goodwill and peace among nations, and it is one of the greatest calamities of history that it could not achieve its objective; but it undertook many important surveys on international affairs, knowledge of which is useful for coming to the heart of the international problem. One is the Year-Book, published by the Labour Organisation of the League, which shows in tabulated form the production of commodities in the different political units of the world. This is indispensable for arriving at a proper estimate of the comparative economic condition of different units. The other was the report of the committee for framing an international calendar for the whole world, which, if it could have been adopted, would have gone a great way to promote goodwill and understanding among the principal nations of the world.
\end{abstract}

The Year-Book must have been very largely used by economists. I myself, while a member of the National Planning Committee of the Indian National Congress $\dagger$, tried to form, from the contents of the Year-Book, some idea of the average per capita income of the different countries of the world. This proved to be an almost hopeless task; but it was thought that an estimate of the same quantity might be obtained from an entirely different angle, namely, the total energy-production in a country, for we can take wealth to be directly proportional to the output of energy. This is a comparatively easier task, for the energy output is mainly due to the following agencies: (1) Work done by man and domesticated animals: (2) Work done by inanimate agencies : mainly engines using coal, petrol, and other kinds of fuel (bagasse or wood). (3) Work done by electricity derived either from thermal (coal or petrol), or from hydro-electric, sources. Other sources of energy output are negligible at the present time.

Suppose we can estimate the energy output under the three headings accurately, add them up, and divide the whole by the total population of the country. We get a figure which shows the average per capita energy output for a country. For the sake of brevity, we shall denote this figure by the term energy-index. Let us now see how to calculate the energy-index for a few representative countries of the world just before the outbreak of the present War.

The League of Nations Year-Book gave total production of electrical energy from thermal and hydroelectric sources against every country, so that it is a perfectly simple matter to calculate the contribution to energy-index from electricity for every country. It was 650 for the United Kingdom, 1,700 for Canada, 1,300 for Sweden, and about 1,500 for the United States. These are the most advanced countries of the

* A lecture delivered before a joint meeting of the British Institute for International Affairs, and the British Association for the Advancement of Science, on November 10, 1944.

$\dagger$ The National Planning Committee was appointed by the president of the Indian National Congress in October 1938, with Pandit Jawaha Lal Nehru as chairman. It appointed twenty-nine sub-committees, held a number of discussions, and framed resolutions for the economic and social regeneration of India. Its activities were terminated in 1941 owing to the incarceration of the chairman. world, but we may also take some others ; the figure was 180 for Mexico, and for progressive countries like the U.S.S.R., it was rapidly increasing from very small figures to those attained by the advanced countries. In countries like Poland, the figure was stationary. For India and China, no figures were available, but according to a Government of India estimate, the total production of electrical energy in India in 1942 was 3,500 million units, so that it comes to only 9 units a head for India. China was rather worse.

It is more difficult to calculate the energy-production from coal or other fuel; for coal mined or imported into a country has many other uses besides energy production, and the efficiency of energy production varies widely. It is not worth while to give all the technical details, but it was concluded that the contribution to the energy-index from coal and other fuel in the United Kingdom amounted to nearly 1,300, and somewhat more in the United States. In India, it could not have been more than 20 , for India produces only 26 million tons of coal against Britain's 200 millions, and the use of Indian coal is extremely wasteful.

We, therefore, find that, before the War, the energy-index in the year from inanimate sources amounted in Britain to about 2,000 and in the United States to about 2,500; in India it could not amount to more than 30 , and even that is probably too liberal an estimate.

Where does the energy production by man and domesticated animals come in this picture? A man working eight hours a day for three hundred days in the year produces only 180 units, and assuming that one third of the population is engaged in productive work, which is not far from the truth, the average cannot be more than 60 units per capita a year. The energy production by animals, by wind and waterpower in the Middle Ages would not exceed 20 units, so we are not far from the truth if we say that in the Middle Ages the energy-index in all countries amounted to about 80 units, with small variations from country to country. This is negligible compared with energy production in a modern country, by steam, electricity and petrol, and can be almost entirely left out. Man's function, in the present days of technocracy, is merely directive.

These arguments are simple enough, but we can draw from them some very important conclusions. It is obvious that in advanced countries of the world, man, by harnessing the forces of Nature, has increased the energy-index by twenty to thirty-five times within the last hundred years, and this has caused a profound revolution in society. Let us see what this revolution is.

Most old-fashioned history books tell us only of kings, emperors, nobility, and of the privileged few, and omit entirely the common man; and from their perusal we are apt to form sometimes a romantic, uncritical picture of ancient and medieval times. But critical historical research has shown that even two hundred years ago the standard of living for the ordinary person, and conditions of public health in every country, were appallingly low compared to modern standards. Only a few who possessed slaves could afford to have some 'comfort', but it was not much compared to the standards now enjoyed even by the ordinary citizen in an advanced country of the world. In the sixteenth century, there was terrible mortality among children, and even royal children used to suffer heavy mortality due to 
diseases now found to be preventable, thanks to science.

The philosophy of kindliness and service to our fellow-men was preached by all founders of great religions, and no doubt some great kings and ministers of religions in every country and at all ages tried to give effect to this (altruistic) philosophy. But the efforts were not successful, for the simple reason that the methods of production of commodities were too inefficient to yield plenty for all, which is an indispensable condition for practical altruism.

We can therefore hold that, so far as individual life is concerned, science has achieved the target aimed at by the great founders of religions in advanced countries of the world. The effects of maldistribution of wealth, due to historical causes, are being rapidly cured by the introduction of social laws.

The advanced States of Europe, and also the United States of America, began to move out of those dreadful medieval conditions during the seventies of the last century, when modern science began to develop and new methods of production were applied on a mass scale. As a result of a century of progress, individual conditions of living and public health have steadily improved in Britain and in many other countries of Europe and America. Probably the best index is afforded by the average life, which has increased from twenty-nine about a hundred and fifty years ago to fifty-eight in 1944 in the United Kingdom; and to sixty-three in the United States, according to reliable reports. Not satisfied with that, Britain is having a social insurance measure on the lines of the Beveridge Plan, which will take care of the man from the 'cradle to the grave'.

\section{Indian Conditions}

Let us now come to my own country--India. Figures have been given which show that the energyindex in India is not more than 100 units, or at best 120 units. It is twenty to thirty times smaller than in the advanced countries of the world. The National Planning Committee estimated the average income of the Indian in 1938 to be Rs. 65 or $£ 5$, which can be compared to the average income of the Britisher about the same time (nearly $£ 120$ ). This figure, when it was published, was challenged, but our method of approach-which is radically different-leads us to an identical conclusion*.

Recently the Royal Society sent a distinguished ambassador of science, Prof. A. V. Hill, to India, and he took pains, as no other man has previously done, to study first-hand the conditions of public health, and to some extent observe the general economic conditions in India. $\mathrm{He}$ has stated his findings publicly, and they are practically the same as mine. By whatever standards you measure, you find 90 per cent of India is still in the Middle Ages. The thin veneer of modernism which travellers find in the great cities of Bombay, Calcutta and Delhi must not lead you astray. Ninety per cent of India is still in the sixteenth century conditions of England. We have terrible child mortality, the conditions of public health are appalling, and 90 per cent of the people have to live in slums. They have scarcely any interest in life, and we are on the brink of disaster, as Prof. Hill has told the British public repeatedly.

- According to a P.E.P. report, the total income of Britain in 1944 was ten thousand million pounds, which makes the per capita income a little more than $£ 200$. This is due to war inflation, and is compensated by the cost of living. In India, the average income has risen during the War, but the cost of living has increased according to official estimates $2 \cdot 6$ times, and according to non-official estimate, nearly $3 \cdot 5$ times.
The National Planning Committee of the Indian National Congress had rightly concluded that India had been almost entirely untouched by modern scientific methods, and if she wanted to pass out of the present dreadful conditions, she must tackle seriously the great task of applying modern scientific and industrial methods for the development of her potential.wealth, as has been done by the U.S.S.R. with signal success within the past twenty-five years.

Is there any indication that the problem is being properly understood by the central or provincial Government circles ? The problem is so urgent that nobody can shut his eyes to it, and one would conclude so from the appointment of many post-war planning committees; but the pronouncements made by these committees from time to time only add to the general confusion. Some advocate road building without trying to find out who are the men who will use the roads, and for what purpose and by what conveyance; some advocate agriculture; others think there is an inherent antagonism between agriculture and industrialization; but the ordinary man only sees that the terms of superannuated officers are extended on higher salaries. The fact is that the planners lack direction from the centre.

It is obvious that the clearest way to define the objective would be to declare that India's per capita income should be progressively increased to modern figures compatible with her resources; and as a necessary first step, India's energy-index should be progressively increased to the figures attained in all modern countries. Let us put a definite target, say 100 units within the next ten years; and we shall also have to use this energy suitably. This is not a large figure, for even pre-war Mpxico used to produce 180 units of energy per head, and we produce now only 9 units. Such a declaration, if it is fortheoming, would convince the people, as nothing else would do, of the Government's seriousness of purpose. The Government would have to set up proper machinery for producing electrical energy within the next ten years, and to find a use for the energy for the benefit of India's masses. Let us look at this figure from another angle. It is slightly larger than the pre-war production of electrical energy in the United Kingdom, and according to a P.E.P. report, nearly $\mathfrak{f} 600,000,000$ was invested in the electrical industries in Britain. Probably a comparable amount will be needed in India, but if the undertakings are properly planned, many of the mistakes committed in the past can be avoided, and a smaller sum may be sufficient. It will also greatly promote trade relations between India and the United Kingdom, as in the case of the U.S.S.R., for India will have to depend for a long time yet to come on imported machinery for her development.

\section{Industry vs. Agriculture}

If a policy of progressive electrification of India be agreed upon and undertaken, we shall have to spend most of the energy produced in industrialization. Many critics have seen in this policy a menace to agriculture and to the agricultural population, and have raised the cry of agriculture versus industry. But this is due to confusion of ideas, and a little thinking shows that there is really no conflict between industry and agriculture. As a matter of fact, the position of agriculture in India has been entirely misunderstood, and misinterpreted.

According to the census figure of 1931, which is the latest available to us, only 15 per cent of the popula- 
tion of India is urban and 85 per cent is rural, of which nearly 70 per cent is directly dependent on agriculture. Anybody having the slightest knowledge of economics knows that this is a very unhealthy sign. Probably with the exception of China, no other country in the world has such a large percentage of her population on the land. In some parts of Bengal, the holding is two-thirds of an acre per head of the population. The remark of Julian Huxley, referring to the Tennessee Valley of twenty years ago, may be applied with far greater emphasis: "Primitive in their reproductive habits as in their farming methods, they multiply rapidly until they present a typical Malthusian population, pressing hard upon the land's capacity for subsistence".

How has this state of affairs been brought about ? We have reasons for believing that before cheap factory goods began to pour into the markets of India, there was a far better balance between the people actually employed in agriculture, and the artisan classes. When industrial revolution started in England, the rural population of England was sucked into production centres, which rapidly grew into large cities, and the urban population grew rapidly. In India, the effect was in the reverse direction. When cheap factory-made goods began to pour into the markets of India, most of the artisan classes-weavers, spinners, blacksmiths, potters and metal workers-lost their jobs and became peasants. With the introduction of railways and steamships, people engaged in the transport trade lost their jobs and were thrown upon the land. The successive famine commissions have rightly diagnosed the excessive pressure on land to be one of the causes of malnutrition and recurrent famines, and recommended that the burden should be taken off the land by providing a large section of the population engaged in agriculture with industrial occupation. But the small amount of industrialization which had taken place in India is totally inadequate for taking the burden off the land.

But one must not forget that in spite of the disproportionately large number of men engaged in agriculture, there is not sufficient margin of safety as regards production of food for India's four hundred millions. The Bengal famine of 1943 appears to have focused the attention of the world on this point, and though this disaster was precipitated by a variety of causes, in which food shortage played a minor part, one must not forget that there is a chronic deficiency of food, both of vegetable and animal origin, and there is consequently permanent malnutrition. India is just on the verge of a crisis, as Prof. Hill has repeatedly stated, and any small cause may precipitate it. The fact is that, owing to over-population, which is itself a consequence of oyer-ruralization, man in India is making too much demand on the soil, which is not allowed to rest or recouperate. A survey of the productivity of the soil of India recently carried out by Dr. Burns, agricultural commissioner to the Government of India, shows that it produces on the average four times less crops than soil in advanced countries, and according to some sporadic investigations, the soil of India is deficient in nitrogen, phosphorus and potash, and, due to the causes just mentioned, productivity is diminishing year by year.

But why does not the Indian peasant use fertilizers to increase the productivity of the soil, as has been done in other countries ? For some reason best known to themselves, neither the Government, nor the Imperial Council of Agricultural Research, has paid any attention to the fertilizer problem, and no synthetic fertilizer industry has grown up in the country which can deliver to the peasant suitable fertilizers at economic prices. According to Dr. Burns, if India is to attain safety in food production, the yield should increase by 30 per cent, and this needs nearly a million tons of nitrogen in the form of ammonium sulphate and other fertilizers. Many parts of India show unmistakable signs of phosphorus deficiency, but nobody has yet surveyed her total needs in this respect.

In short, a native fertilizer industry is indispensable for greater agricultural production, and this alone will consume a large amount of the electrical energy to be produced. But this is not all.

The Indian agriculturist, like agriculturists in other parts of the world, cannot depend upon food crops alone. He has to raise also cash erops such as cotton, jute, sugar, oil seeds and tobacco, each one of which is useless unless it is utilized industrially. Fortunately, the corresponding industries have developed in India, though there is far more scope in this direction. India has almost none, or few, food-processing industries, and her excellent and wide variety of fruits are on the market only for $\mathbf{a}$ limited season. There is a great future in this line, but no food-processing industry can flourish without the refrigeration industry. Further, as Sir Harold Hartley has told us in his Mather Lecture, agriculture and forestry can serve as a potential source of raw materials in scores of industries-such as the manufacture of rayon, paper, plastics, liquid fuel, industrial gases-and the development of all these industries requires cheap power.

There is therefore no inherent antagonism between industry and agriculture; and without development of agricultural industries, the rural population of India can never be pulled out of the dreadful medieval conditions in which they find themselves, breeding a Malthusian population which has been a matter of extreme concern to the rulers. For urbanization means better living, and better living leads to moderate increase of population.

\section{Natural Resources of India}

But has India sufficient resources for a balanced development of industries and agriculture on the lines just indicated? According to a competent authority, India, like the United States of America, the U.S.S.R. and China, is one of the few political units of the world which has enough potential resources in power, minerals, and forest and agricultural products, for a balanced development of industry and agriculture to produce plenty for her population. The first problem to be tackled is that of power. India has, according to the work carried out by the Geological Survey of India, 60,000 million tons of coal within the first thousand feet of the surface. This is a comparatively small figure compared to the enormous resources of Great Britain and the United States, and most of these deposits are to be found in a small region in eastern India. But she has plenty of "white coal' - water-power resources-awaiting development; According to a very imperfect survey-or should I say an intelligent guess-carried out nearly twenty years ago by an officer of the Government of India, her water-power resources amount to nearly 20 million* kilowatts, and so far only half a million

* The water-power resources of pre-war Russia were estimated in Czarist days to be $\mathbf{1 4}$ million kilowatts. A detailcd survey carried out early in the Five-Year Plan pushed up the figure to 280 million
kilowatts. 
kilowatts have been developed. But the figure is probably a gross under-estimate as in the case of the U.S.S.R. The first problem before the Government of India should be, therefore, to carry out an adequate survey of the hydro-electric resources of India, and plan for the development of ample power for industries.

Civilized life in India has, from time immemorial, grown in river-valleys, which have been used for navigation and irrigation. During the British regime, development has been one-sided, namely, for irrigation only, and navigation has been allowed to fall into decay. But both Soviet Russia and the United States of America have, within the last twenty-five years, set a new ideal for river development. We can take, as a typical illustration, the development of the Tennessee River, which before 1933 was a matter of great concern to the Federal Government on account of the destructive floods, soil erosion, and progressive pauperization of dwellers of the valley. But it is now well known, thanks to the initiative of American statesmen, that this river has been completely transformed by the construction of twenty-one dams over the main river and tributaries. These dams serve the multiple purpose of flood-prevention, navigation and power development, and soil erosion has been prevented by auxiliary measures. The hitherto untamed river, instead of being allowed to dissipate its energy on destructive work, is now harnessed and yields 12,000 million units of electrical energy, which is used for great productive works which have sprung up in the valley (metallurgical, chemical and fertilizer industries).

The multi-purpose development of a river valley, the benefits of which have been so strikingly demonstrated by the Tennessee Valley Authority, is applicable to at least a score of river valleys in India. I have made a particular study of the Damodar Valley, an area of 9,000 square miles, which forms the country to the west of the great city of Calcutta. The lower part of this valley, forming the suburban area of Calcutta, was, a hundred years ago, one of the healthiest regions of the world. But after the construction of railways from 1850, and great roads to connect Calcutta with upper India, embankments were reinforced and constructed on the left bank of the river in order to protect these highways from the destructive river floods. These embankments have by no means removed the danger to the highways; for in 1943 there was only a moderate flood which breached the line at numerous points, and seriously interfered with traffic to Calcutta at a very critical period of the history of the country. They have, in addition, turned the country into a malarial swamp. Even the safety of Calcutta is endangered.

I have shown by a preliminary study that this valley can be subjected to the same treatment as the Tennessee, and can be developed for energy generation (to the extent of 2,000 million $\mathrm{kW}$. a year), navigation, and flood prevention. The lower valley can be transformed by auxiliary methods of irrigation into a fine suburban area, where the teeming population of Calcutta can expand.

But the Damodar Valley is not unique. The Sone, the rivers of the Deccan (the Kaveri has been developed to some extent), the Mahanadi, the Punjab rivers, and many others too numerous to mention, can be developed according to the T.V.A. methods for the benefit of India's millions.

This is only a cursory survey of the problems of India and of the way in which we have to look at it.
It is regrettable that the Indian leaders have so far paid attention only to the question of political freedom. It is natural that everyone of us should want our country to attain full nationhood and the people have full sovereignty, but the problem of living for millions of Indians cannot be postponed; in fact, we believe that the only way to achieve unity of thought and purpose in the political field, which is now wanting, is first to look at the problem of living for India's millions. To solve this problem successfully there must be a national purpose behind all planning, and I do not see how any planning can be given effect without a National Government, or unless we have a Government which has popular support and is composed of leaders in whom the people have confidence.

\section{ASTRONOMICAL AND GEOPHYSICAL PERIODICITIES}

A GEOPHYSICAL Discussion on "Astronomical A and Geophysical Periodicities" was held in the rooms of the Royal Astronomical Society on December 8, 1944 ; the chair was taken by Prof. L. M. Milne-Thomson, and in the absence of Dr. Harold Jeffreys through indisposition, the discussion was opened by Dr. H. R. Hulme.

Dr. Hulme's interest in this problem originally arose in connexion with the reality of the supposed periodical variations in the solar constant. Any time-series of observations can be analysed by the routine method of harmonic analysis, and amplitudes will be obtained which will not in general be zero, even when there is not the slightest reason for suspecting the presence of a periodic variation; such an analysis has, in fact, often been carried out with geophysical data. The first attempt to find a criterion for the reality of a periodic term was made in 1906 by Sir Arthur Schuster, who found that if $n$ independent observations were analysed into their Fourier components the average amplitude $\rho$ of a Fourier coefficient is $2 \sigma / n^{1 / 2}$, where $\sigma$ is the standard deviation of the $n$ observations ; if, then, the observed amplitude is $p_{0}$, the chance that such a component could arise purely as a result of random fluctuations is $e^{-k}$, where $k=\rho_{0}^{2} / \rho^{2}$. Thus, if the amplitude found is more than twice $p$, there is some ground for suspecting that the periodicity may be real.

The Schuster criterion, however, takes no account of internal correlations among the data. Thus a naive view of the problem may give misleading results ; if, for example, the observations are subject to disturbances, each of which affects a number of consecutive observations, the effective number of independent observations may be far less than $n$. Moreover, the criterion is of limited usefulness, since an investigator who thought that the values of a series of observations were all independent of one another would not be likely to make a harmonic analysis of the results. A more searching method of analysing a time-series was given in 1927 by $\mathrm{Mr}$. G. Udny Yule. He considered two types of periodicities : the periodic phenomena where each disturbance affects only the momentary value of the quantity observed; and periodic phenomena in which each disturbance affects all the subsequent values, as, for example, a change of phase. The latter type would be discussed by Mr. M. G. Kendall. Dr. Hulme pointed out that an outstanding problem is to find 